\title{
High-fat diet intake from senescence inhibits the attenuation of cell functions and the degeneration of villi with aging in the small intestine, and inhibits the attenuation of lipid absorption ability in SAMP8 mice
}

\author{
Kazushi Yamamoto, Shuang E, Yu Hatakeyama, Yu Sakamoto and Tsuyoshi Tsuduki* \\ Laboratory of Food and Biomolecular Science, Graduate School of Agriculture, Tohoku University, Aoba-ku, Sendai 981-8555, Japan
}

(Received 27 April, 2015; Accepted 25 May, 2015; Published online 9 September, 2015)

\begin{abstract}
We examined the effect of a high-fat diet from senescence as a means of preventing malnutrition among the elderly. The senescence-accelerated mouse P8 was used and divided into three groups. The $6 \mathrm{C}$ group was given a normal diet until 6 months old. The $12 \mathrm{~N}$ group was given a normal diet until 12 months old. The $12 \mathrm{~F}$ group was given a normal diet until 6 months old and then a high-fat diet until 12 months old. In the oral fat tolerance test, there was a decrease in area under the curve for serum triacylglycerol level in the $12 \mathrm{~N}$ group and a significant increase in the $12 \mathrm{~F}$ group, suggesting that the attenuation of lipid absorption ability with aging was delayed by a highfat diet from senescence. To examine this mechanism, histological analysis in the small intestine was performed. As a result, the degeneration of villi with aging was inhibited by the high-fat diet. There was also a significant decrease in length of villus in the small intestine in the $12 \mathrm{~N}$ group and a significant increase in the $12 \mathrm{~F}$ group. The high-fat diet from senescence inhibited the degeneration of villi with aging in the small intestine, and inhibited the attenuation of lipid absorption ability.
\end{abstract}

Key Words: aging, high fat diet, lipid absorption, SAMP8, small intestine

$\mathrm{T}$ he population of elderly persons is increasing worldwide, making it important to study mechanisms of aging. Senescence is defined as age-related changes in physiological function and aging depresses tissue functions such as decreasing lipid metabolism ability in the liver and insulin secretion ability in the pancreas. ${ }^{(1-4)}$ To delay senescence, maintain quality of life for the elderly and die a natural death, it is important to consider diet and nutrition. ${ }^{(5)}$

Malnutrition is one of the nutrition problems of the elderly. Malnutrition induces loss of motor function, delays recovery from disease and increases the rate of complications and death. ${ }^{(6,7)}$ One cause of malnutrition is the decreased ability of the gastrointestinal tract to absorb nutrients. ${ }^{(8)}$ However, this mechanism is not well understood. In our previous study, we examined lipids, which are an important nutrient, and showed the progression of senescence of the pancreas, which is related to lipid absorption ability, and found that lipid absorption ability was reduced by decreased expression of pancreatic lipase in aged mice. ${ }^{(5)}$ In addition, we necropsied deceased mice and observed the interesting phenomenon that body weight decreased dramatically and visceral fat disappeared in mice that were approaching death. This suggests that delaying the phenomenon by slowing the attenuation of lipid absorption ability with aging may prolong life.

A high-fat diet is a diet which includes many lipids. Mice fed a high-fat diet from a young age are susceptible to fatty liver and diabetes, and a high-fat diet is considered poor for health. ${ }^{(3,9)}$ However, it was shown that elderly people who consume much fat lived longer, prompting a second look at high-fat diets. ${ }^{(10)}$ Although a high-fat diet may have a beneficial effect of increasing life expectancy, few studies have examined this. It was reported that lipid absorption ability in the small intestine increases in mice fed a high-fat diet from 6 to 9 weeks of age. ${ }^{(11)}$ Therefore, a highfat diet may delay the attenuation of lipid absorption ability with aging and reduce malnutrition in the elderly. However, a high-fat diet from a young age induces aging-related diseases such as fatty liver and diabetes.

In this study, we examined the effect of a high-fat diet from senescence as a means of delaying the attenuation of lipid absorption ability with aging. We used the senescence-accelerated mouse (SAM) P8. SAM was developed in 1981 at Kyoto University and there are various senescence-prone inbred strains (SAMP1, P2, P3, P6, P7, P8, P9, P10). ${ }^{(12,13)}$ The SAMP8 mouse shows normal growth and then senescence progresses from 6 months of age. In addition, this mouse exhibits aging amyloidosis, the attenuation of immune function and learning and memory disorder. ${ }^{(14,15)}$ The SAMP8 mouse has a lifespan of about a year and it is widely used for analysis of mechanisms of aging and dietary components. ${ }^{(16,17)}$ In this study, we examined the effect of lipid absorption ability in the SAMP8 mouse fed a high-fat diet from senescence (6 months of age).

\section{Materials and Methods}

Animals and diets. All procedures were performed in accordance with the Animal Experiment Guidelines of Tohoku University. The animal protocol was approved by the Animal Use Committee at Tohoku University. ${ }^{(18)}$ Male SAMP8 mice (11 weeks of age) were obtained from Japan SLC (Hamamatsu, Japan). After acclimatization to a commercial diet (CE-2; CLEA Japan, Tokyo, Japan) for 1 week, the mice received a control diet (CE-2) until age 6 months, then they were randomly divided into three groups that were sacrificed or received different com-

To whom correspondence should be addressed.

E-mail: tsudukit@m.tohoku.ac.jp 
Table 1. Primer pairs used for the quantitative RT-PCR analysis

\begin{tabular}{|c|c|c|c|}
\hline Genbank ID & Target gene & Primer & Primer sequence $\left(5^{\prime}-3^{\prime}\right)$ \\
\hline NM_007393 & Actb & $\begin{array}{l}\text { Forward } \\
\text { Reverse }\end{array}$ & $\begin{array}{l}\text { GAAATCGTGCGTGACATCAAAG } \\
\text { TGTAGTTTCATGGATGCCACAG }\end{array}$ \\
\hline NM_025469 & Clps & $\begin{array}{l}\text { Forward } \\
\text { Reverse }\end{array}$ & $\begin{array}{l}\text { GCTCTTGCCTTCTGCTGTCTGA } \\
\text { ATGGCGCCGATGATGCTCCTGT }\end{array}$ \\
\hline NM_007824 & Cyp7a1 & $\begin{array}{l}\text { Forward } \\
\text { Reverse }\end{array}$ & $\begin{array}{l}\text { GGGATTGCTGTGGTAGTGAGC } \\
\text { GGTATGGAATCAACCCGTTGTC }\end{array}$ \\
\hline NM_007980 & Fabp2 & $\begin{array}{l}\text { Forward } \\
\text { Reverse }\end{array}$ & $\begin{array}{l}\text { AGAGGAAGCTTGGAGCTCATGACA } \\
\text { TCGCTTGGCCTCAACTCCTTCATA }\end{array}$ \\
\hline NM_008642 & Mttp & $\begin{array}{l}\text { Forward } \\
\text { Reverse }\end{array}$ & $\begin{array}{l}\text { AGTGCAGTTCTCACAGTACCCGTT } \\
\text { AGCATATCGTTCTGGTGGAAGGGA }\end{array}$ \\
\hline NM_001111099 & p21 & $\begin{array}{l}\text { Forward } \\
\text { Reverse }\end{array}$ & $\begin{array}{l}\text { CCTGGTGATGTCCGACCTG } \\
\text { CCATGAGCGCATCGCAATC }\end{array}$ \\
\hline NM_011128 & Plrp2 & $\begin{array}{l}\text { Forward } \\
\text { Reverse }\end{array}$ & $\begin{array}{l}\text { ATGCCTATGGATGTCCGTGGA } \\
\text { TGCCCAGGGCTTGTCATTG }\end{array}$ \\
\hline NM_026925 & Ptl & $\begin{array}{l}\text { Forward } \\
\text { Reverse }\end{array}$ & $\begin{array}{l}\text { CTGGGAGCAGTAGCTGGAAG } \\
\text { AGCGGGTGTTGATCTGTGC }\end{array}$ \\
\hline
\end{tabular}

Actb, actin beta; Clps, colipase; Cyp7a1, cholesterol 7 $\alpha$-hydroxylase; Fabp2, fatty acid-binding protein 2; Mttp, microsomal triglyceride transfer protein; Plrp2, pancreatic lipase-rerated protein; Ptl, pancreatic lipase.

mercial diets: a group given control diet (CE-2) and a group given high-fat diet (Quick Fat; CLEA Japan). The control diet or high-fat diet composition ( $\mathrm{g} / 100 \mathrm{~g}$ diet) was nitrogen-free extract, 51.0 or 46.7 ; crude protein, 24.9 or 24.8 ; crude fat, 4.6 or 14.4 ; crude ash, 6.6 or 5.0 ; crude fiber, 4.1 or 2.5 ; moisture, 8.9 or 6.8 . The control diet or high-fat diet calorie content ( $\mathrm{kcal} / 100 \mathrm{~g}$ diet) was 345 or 415 . The energy of the high-fat diet was about $20 \%$ higher than that of the control diet. Twenty mice which received the control diet were sacrificed for analysis at age 6 months $(6 \mathrm{C}$; $n=9$, one mouse died on the way) and 12 months $(12 \mathrm{~N} ; n=8$, two mice died on the way). Ten mice which received the high-fat diet from age 6 months were sacrificed for analysis at age 12 months $(12 \mathrm{~F} ; n=6$, four mice died on the way). The mice were housed in individual cages with free access to commercial diets and distilled water in a temperature- and humidity-controlled room with light cycles of $12 \mathrm{~h}$ on and $12 \mathrm{~h}$ off. ${ }^{(19)}$ At the appropriate time point, the mice were weighed and then sacrificed by decapitation, and brain, heart, kidney, lung, liver, pancreas, spleen, thymus, mesenteric adipose tissue, perirenal adipose tissue, epididymal adipose tissue, small intestine and serum were collected and stored at $-80^{\circ} \mathrm{C}$ until the assays were performed.

Oral fat tolerance tests. After overnight fasting of mice aged 6 and 12 months, $5 \mathrm{~g}$ of soybean oil per kg body weight was administered orally. Blood samples were collected by cutting tissue from the tail tip and then massaging the tail. Serum triacylglycerol (TG) levels were measured at $0,1,2,3,4,5$ and $6 \mathrm{~h}$ with an enzyme kit (Wako Pure Chem., Ind., Ltd., Osaka, Japan). Serum TG levels were determined using the TG kit (Wako Pure Chem.), and the area under the curve for blood TG (AUC) was calculated.

Thiobarbituric acid-reactive substance assay. To examine oxidative stress caused by aging, the levels of thiobarbituric acidreactive substances (TBARS) in serum, liver, pancreas and small intestine were measured as described previously. ${ }^{(20,21)}$

mRNA expression analysis. For real-time quantitative reverse transcriptase PCR (qRT-PCR), total RNA was isolated from liver, pancreas and small intestine using an RNeasy Mini Kit (Qiagen, Valencia, CA), ${ }^{(3,22)}$ eluted with 90-200 $\mu$ l RNase-free water, and stored at $-80^{\circ} \mathrm{C}$ until use. To quantify the expression levels of genes, mRNA levels for beta-actin (Actb), colipase (Clps), cholesterol $7 \alpha$-hydroxylase (Cyp7a1), fatty acid-binding protein 2 (Fabp2), microsomal triglyceride transfer protein (Mttp), p21, pancreatic lipase-related protein 2 (Plrp2) and pancreatic lipase (Ptl) in liver, pancreas and small intestine were determined with a Thermal Cycler Dice Real Time System ${ }^{\circledR}$ (Takara Bio, Otsu, Japan). This system allows real-time quantitative detection of PCR products by measuring the increase in fluorescence caused by binding of SYBR green to double-stranded DNA. ${ }^{(3,23)}$ In brief, cDNA was made using Prime Script ${ }^{\mathbb{B}}$ RT Master Mix (Perfect Real Time) (Takara Bio) from total RNA in liver, pancreas and small intestine. The cDNA was subjected to PCR amplification using SYBR ${ }^{\circledR}$ Premix Ex Taq ${ }^{\mathrm{TM}}$ (Perfect Real Time) (Takara Bio) and gene-specific primers for Actb, Clps, Cyp7a1, Fabp2, Mttp, p21, Plrp2 or Ptl (Table 1). The PCR amplification was performed with an activation step at $95^{\circ} \mathrm{C}$ for $10 \mathrm{~s}$, followed by 40 cycles at $95^{\circ} \mathrm{C}$ for $5 \mathrm{~s}$ (denaturation) and $60^{\circ} \mathrm{C}$ for $31 \mathrm{~s}$ (extension), and a dissociation stage at $95^{\circ} \mathrm{C}$ for $15 \mathrm{~s}, 60^{\circ} \mathrm{C}$ for $30 \mathrm{~s}$ and $95^{\circ} \mathrm{C}$ for $15 \mathrm{~s}$ for each gene. Melting curve analysis was performed following each reaction to confirm the presence of only a single reaction product. The threshold cycle $\left(\mathrm{C}_{\mathrm{T}}\right)$ represents the PCR cycle at which an increase in reporter fluorescence above a baseline signal can first be detected. The ratio between the Actb content in standard samples and test samples was defined as the normalization factor. ${ }^{(24)}$

Histological analysis. For histological analysis of the small intestine, tissues of each mouse were fixed in $10 \%$ formalin and embedded in paraffin. ${ }^{(25)}$ Vertical sections were cut, mounted on a glass slide, stained with hematoxylin and eosin, and observed using a microscope (BZ-9000; Keyence, Osaka, Japan). The length of villus in the small intestine was measured by using image analysis software (BZ-9000). We calculated means by measuring 40 sites at random for each sample.

DNA microarray analysis. Total RNA was isolated from the small intestine using an RNeasy Mini Kit (Qiagen, Valencia, CA), ${ }^{(3,22)}$ eluted with 90-200 $\mu \mathrm{l}$ RNase-free water, and stored at $-80^{\circ} \mathrm{C}$ until use. DNA microarray analysis (Super Print G3 Mouse GE $8 \times 60 \mathrm{~K}$ Microarray; Agilent) using total RNA was performed by Takara Bio. Total RNA was pooled for each group and subjected to DNA microarray analysis. ${ }^{(2)}$ Gene expression ratio is shown as " $\log _{2}$ Ratio".

Biochemical analyses in plasma and liver. The lipid compositions in the liver and serum were measured as described previously. ${ }^{(26,27)}$ TG and total cholesterol (TC) levels in serum and liver, and phospholipid (PL) and glucose levels in serum were measured using commercial enzyme kits (Wako Pure Chem.) according to the manufacturer's protocol. Insulin was determined using ELISA kits (Shibayagi, Shibukawa, Japan). ${ }^{(27)}$ PL levels in liver were determined using the method described by Rouser. ${ }^{(28)}$ 
Statistical analysis. All statistical analyses were performed using Ekuseru-Toukei 2012 (SSRI, Tokyo, Japan). Results were expressed as means \pm SE. Data were analyzed by a one-way ANOVA with a Tukey post hoc test. Food intake and caloric intake were analyzed by Student's $t$ test. We estimated survival curves for each diet group using the Kaplan-Meier method and tested for differences in survival among the groups with a log rank tests (Supplemental Fig. 1*). A difference was considered to be significant at $p<0.05$.

\section{Results}

Oral fat tolerance tests. To examine the alteration of lipid absorption ability by a high-fat diet from senescence, we conducted oral fat tolerance tests. First, $5 \mathrm{~g}$ of soybean oil per
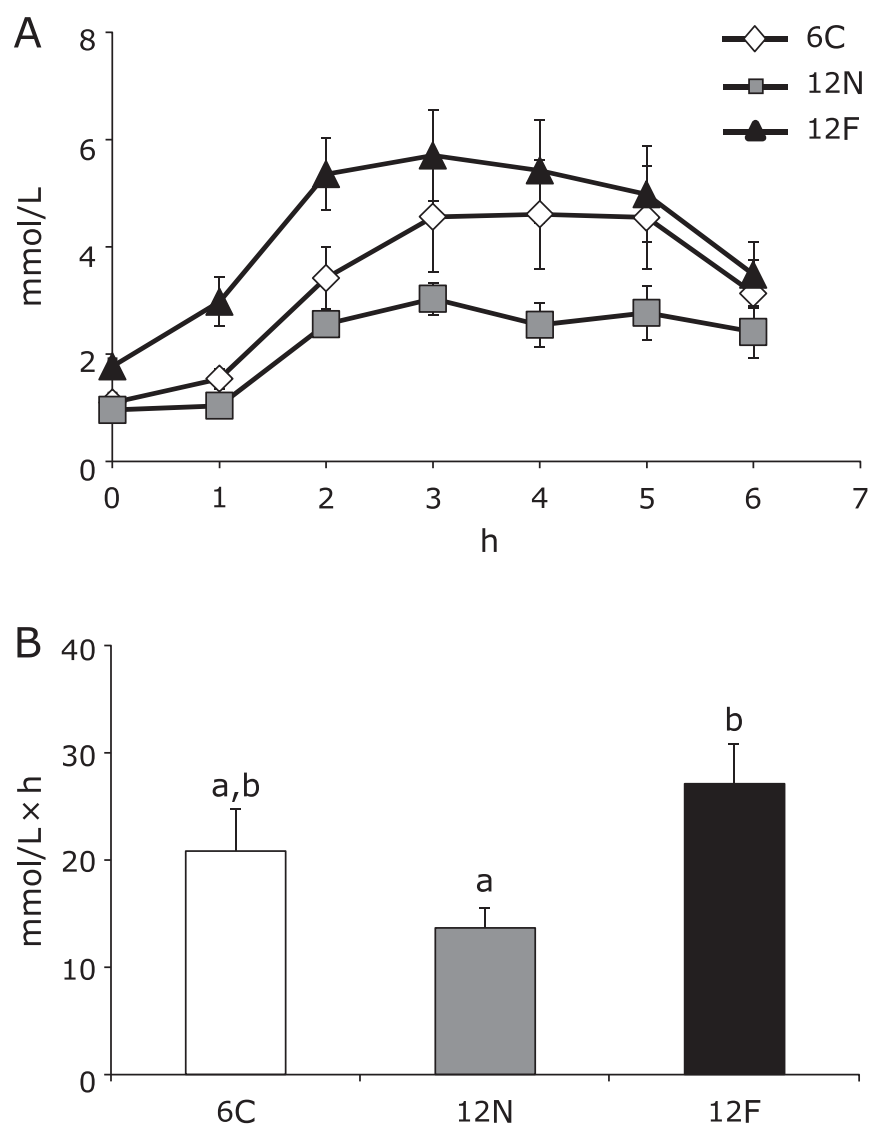

Fig. 1. Effects of aging on lipid absorption ability in SAMP8 mice. Oral fat tolerance test (A) and area under the curve (AUC) (B) are shown. Values are means $\pm \mathrm{SE}, n=6-9$. ${ }^{\mathrm{a}, \mathrm{b}} p<0.05$. kilogram body weight was administered orally and serum TG levels were measured at $0,1,2,3,4,5$ and 6 h (Fig. 1A). As a result, serum TG levels gradually increased by consumption of soybean oil and peaked at 3-4 h in all groups. At all times, serum TG levels showed the highest values in the $12 \mathrm{~F}$ group and the lowest values in the $12 \mathrm{~N}$ group. There was a significant increase in AUC for serum TG levels in the $12 \mathrm{~F}$ group compared to the $12 \mathrm{~N}$ group (Fig. 1B). This suggested that the attenuation of lipid absorption ability with aging can be delayed by a high-fat diet from senescence.

Senescence indicator in serum, liver, pancreas and small intestine. To examine the degree of aging in SAMP8 mice, the lipid peroxide (TBARS) and p21 mRNA levels were examined in serum and TG absorption-related tissues (liver, pancreas and small intestine) (Table 2). There was a significant increase in TBARS for serum in the $12 \mathrm{~F}$ group compared to the $6 \mathrm{C}$ group. There was a significant increase in TBARS for liver in the $12 \mathrm{~F}$ group compared to the $6 \mathrm{C}$ and $12 \mathrm{~N}$ groups. There was no significant difference in TBARS for pancreas and small intestine. There was a significant increase in p21 mRNA level for liver in the $12 \mathrm{~N}$ group compared to the $6 \mathrm{C}$ group. There was no significant difference in p21 mRNA level for pancreas and small intestine. These results showed clear progression of senescence in the liver of 12month-old SAMP8 mice.

mRNA levels for TG absorption-related genes in liver, pancreas and small intestine. To examine the effect of a highfat diet on the attenuation of lipid absorption ability with aging, the expression of mRNA for TG absorption-related genes in liver, pancreas and small intestine was measured (Table 3 ). There was no significant difference in the mRNA level of Cyp7a1 which is crucial for bile acid synthesis in the liver. There was no significant difference in the mRNA levels of Clps, Plrp2 and Ptl which are required for efficient TG hydrolysis in the pancreas. There was no significant difference in the mRNA levels of Fabp2 which transports free fatty acid and Mttp which brings TG into chylomicrons in the small intestine. This suggested that there was no change in mRNA levels for TG absorption-related genes in relation to the delay of the attenuation of lipid absorption ability by a high-fat diet.

Histological analysis in small intestine. To examine the reason why the lipid absorption ability decreased with aging and the decrease was inhibited by a high-fat diet, histological analysis was performed in the small intestine, which is important for lipid absorption (Fig. 2A). As a result, the length of villus in the small intestine diminished in the $12 \mathrm{~N}$ group compared to the $6 \mathrm{C}$ group. On the other hand, there was no difference in the length of villus in the small intestine between the $6 \mathrm{C}$ and $12 \mathrm{~F}$ groups. The length of villus in the small intestine was measured. There was a significant decrease in the length of villus in the small intestine in the $12 \mathrm{~N}$ group and a significant increase in the $12 \mathrm{~F}$ group compared to the $6 \mathrm{C}$ group (Fig. 2B). This suggested that the length of villus in the small intestine diminishes with aging but this decrease is inhibited by a high-fat diet.

Table 2. Senescence indicator in mice

\begin{tabular}{lccc}
\hline & $6 \mathrm{C}$ & $12 \mathrm{~N}$ & $12 \mathrm{~F}$ \\
\hline TBARS & & & $5.49 \pm 0.48^{\mathrm{b}}$ \\
$\quad$ Serum $(\mu \mathrm{mol} / \mathrm{L})$ & $2.78 \pm 0.71^{\mathrm{a}}$ & $3.61 \pm 0.37^{\mathrm{a}, \mathrm{b}}$ & $268 \pm 65.2^{\mathrm{b}}$ \\
$\quad$ Liver $(\mathrm{nmol} / \mathrm{g})$ & $96.5 \pm 8.75^{\mathrm{a}}$ & $127 \pm 11.6^{\mathrm{a}}$ & $248 \pm 24.4$ \\
$\quad$ Pancreas $(\mathrm{nmol} / \mathrm{g})$ & $338 \pm 21.0$ & $269 \pm 38.9$ & $144 \pm 20.6$ \\
$\quad$ Small intestine (nmol/g) & $421 \pm 190$ & $248 \pm 71.9$ & $5.91 \pm 0.92^{\mathrm{a}, \mathrm{b}}$ \\
p21mRNA expression & & & $1.75 \pm 0.48$ \\
$\quad$ Liver (Ratio) & $1.00 \pm 0.13^{\mathrm{a}}$ & $6.63 \pm 2.44^{\mathrm{b}}$ & $1.02 \pm 0.11$ \\
$\quad$ Pancreas (Ratio) & $1.00 \pm 0.28$ & $0.99 \pm 0.22$ & $0.71 \pm 0.05$ \\
$\quad$ Small intestine (Ratio) & $1.00 \pm 0.11$ & &
\end{tabular}

Values are means $\pm S E, n=6-9 .{ }^{a, b} p<0.05$. TBARS, thiobarbituric acid active substance. 
Table 3. mRNA expression levels for triacylglycerol absorption-related genes in liver, pancreas and small intestine of mice.

\begin{tabular}{|c|c|c|c|}
\hline & $6 C$ & $12 \mathrm{~N}$ & $12 \mathrm{~F}$ \\
\hline & & (Ratio) & \\
\hline \multicolumn{4}{|l|}{ Liver } \\
\hline Cyp7a1 & $1.00 \pm 0.20$ & $2.36 \pm 0.58$ & $1.50 \pm 0.35$ \\
\hline \multicolumn{4}{|l|}{ Pancreas } \\
\hline Clps & $1.00 \pm 0.28$ & $1.18 \pm 0.18$ & $1.48 \pm 0.42$ \\
\hline Plrp2 & $1.00 \pm 0.28$ & $1.10 \pm 0.16$ & $1.54 \pm 0.41$ \\
\hline Ptl & $1.00 \pm 0.28$ & $1.05 \pm 0.15$ & $1.37 \pm 0.31$ \\
\hline \multicolumn{4}{|c|}{ Small intestine } \\
\hline Fabp2 & $1.00 \pm 0.12$ & $0.82 \pm 0.14$ & $1.13 \pm 0.21$ \\
\hline Mttp & $1.00 \pm 0.21$ & $1.31 \pm 0.21$ & $1.43 \pm 0.19$ \\
\hline
\end{tabular}

Values are means $\pm \mathrm{SE}, n=6-9$. Cyp7a1, cholesterol 7 $\alpha$-hydroxylase; Clps, colipase; Plrp2, pancreatic lipase-related protein; Ptl, pancreatic lipase; Fabp2, fatty acid-binding protein 2; $M t t p$, microsomal triglyceride transfer protein.

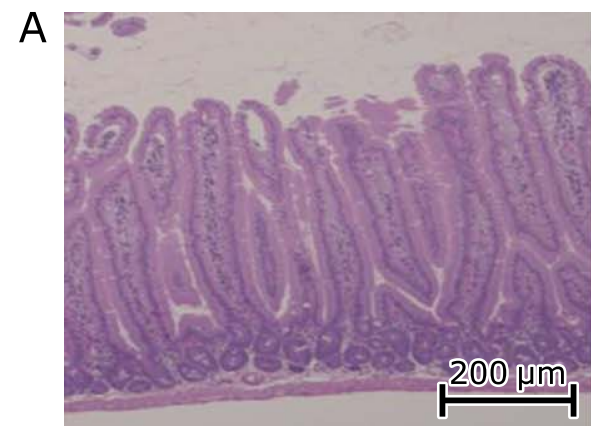

$6 C$

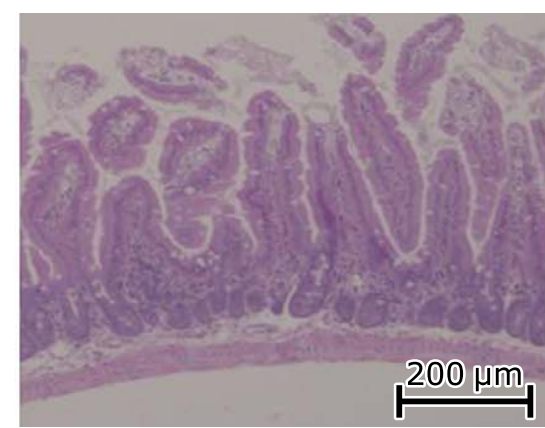

$12 \mathrm{~N}$

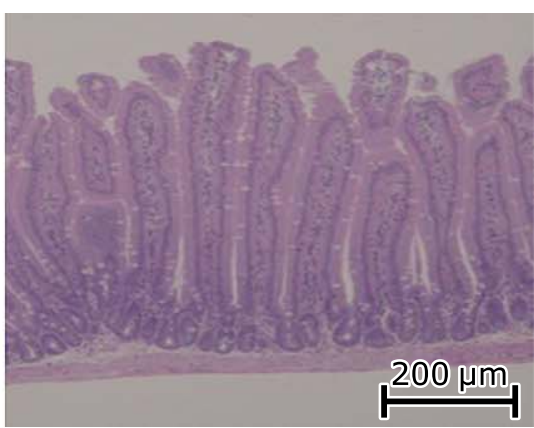

$12 \mathrm{~F}$

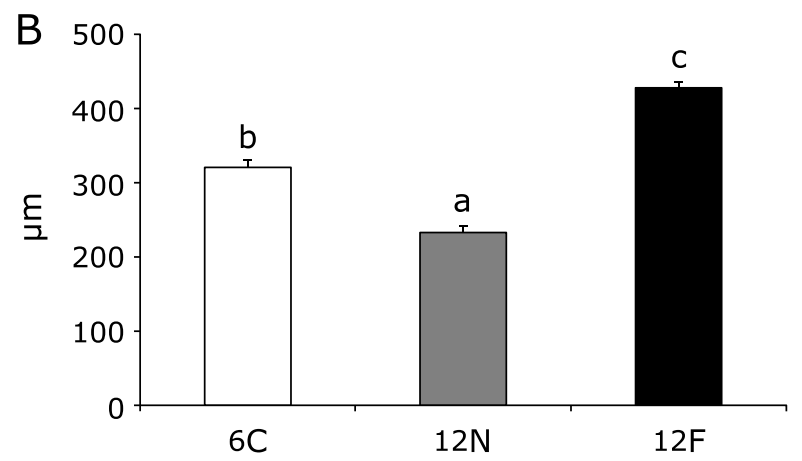

Fig. 2. Effects of aging on histology of small intestine in SAMP8 mice. Small intestines were fixed in $10 \%$ formalin and embedded in paraffin. Sections were cut, mounted on a glass slide and stained with hematoxylin and eosin. Images (A) and mean length (B) of villus in the small intestine of mice are shown. Values are means $\pm \mathrm{SE}, n=3$. ${ }^{\mathrm{a}, \mathrm{b}, \mathrm{c}} \mathrm{c}<0.05$

DNA microarray analysis in small intestine. In the histological analysis, the decrease in the length of villus in the small intestine with aging was inhibited by a high-fat diet. To examine this mechanism, the expression of cell function-related genes in the small intestine was measured by DNA microarray analysis (Table 4). The genes which showed increased or decreased (more than 2-fold difference in $\log _{2}$ ratio) mRNA levels in the $12 \mathrm{~N}$ group compared to the $6 \mathrm{C}$ group were examined. A total of 55 genes were found. The expression of many genes increased. Four metabolism-related genes, three aging and stress response-related genes, six cell structure-related genes and three cell cycle-related genes increased. These genes were listed and examined in detail. The expression of 16 genes changed with aging ( $6 \mathrm{C}$ vs $12 \mathrm{~N})$, but the change in expression of all genes was diminished by a high-fat
Table 4. Cell function related genes from DNA microarray analysis in small intestine: Number of gene transcripts with more than 2-fold difference in $\log _{2}$ ratio between $6 \mathrm{C}$ and $12 \mathrm{~N}$

\begin{tabular}{lcc}
\hline \multirow{2}{*}{ Function } & \multicolumn{2}{c}{ Ratio } \\
\cline { 2 - 3 } & Up & Down \\
\hline Lipid, sugar or protein metabolism & 4 & 0 \\
Stress response/aging/autophagy & 3 & 0 \\
Cell structure/growth/adhesion & 6 & 0 \\
Cell cycle/apoptosis & 3 & 0 \\
Others & 31 & 8 \\
Total & 47 & 8 \\
\hline
\end{tabular}


Table 5. Cell function related genes from DNA microarray analysis in small intestine: list of gene transcripts with more than 2-fold difference in log ratio between $6 \mathrm{C}$ and $12 \mathrm{~N}$

\begin{tabular}{|c|c|c|c|c|c|}
\hline \multirow{2}{*}{ Genebank ID } & \multirow{2}{*}{ Gene name } & \multicolumn{2}{|c|}{$\log _{2}$ ratio (vs $6 C$ ) } & \multirow{2}{*}{ Function } & \multirow{2}{*}{ Classification } \\
\hline & & $12 \mathrm{~N}$ & $12 \mathrm{~F}$ & & \\
\hline NM_001145830 & Plcb1 & 2.09 & 0.89 & Phosphatidylinositol metabolism & Lipid metabolism \\
\hline NM_007502 & Atp1b3 & 2.19 & 0.79 & Insulin secretion & Sugar metabolism \\
\hline NM_009204 & SIc2a4 & 2.14 & 0.69 & Insulin signaling pathway & \\
\hline NM_009932 & Col4a2 & 2.03 & 0.57 & Protein digestion and absorption & Protein metabolism \\
\hline NM_013487 & $C d 3 d$ & 2.02 & -0.24 & T cell receptor signaling pathway & Stress response/Aging/Autophagy \\
\hline NM_010560 & $1 / 6 s t$ & 2.01 & 0.28 & Cytokine receptor interaction & \\
\hline NM_010931 & Uhrf1 & 2.00 & 0.72 & Putative E3 ubiquitin-protein ligase & \\
\hline NM_134142 & Tmem109 & 2.44 & 0.97 & Endoplasmic reticulum membrane & Cell structure/Growth/Adhesion \\
\hline NM_008597 & Mgp & 2.44 & 0.87 & Organic matrix of bone and cartilage & \\
\hline NM_008722 & Npm1 & 2.26 & 0.41 & Ribosome biogenesis & \\
\hline NM_080451 & Synpo2 & 2.08 & 0.71 & Actin-binding and actin-bundling & \\
\hline NM_026631 & Nhp2 & 2.04 & 0.63 & Ribosome biogenesis & \\
\hline NM_011654 & Tuba1b & 2.03 & 0.45 & Phagosome & \\
\hline NM_008563 & $\mathrm{Mcm3}$ & 2.50 & -0.75 & Cell cycle & Cell cycle/Apoptosis \\
\hline NM_182990 & Ssrp1 & 2.11 & 0.29 & Transcriptional coactivator for p63/TP63 & \\
\hline NM_013929 & Siva 1 & 2.00 & 0.45 & Apoptosis & \\
\hline
\end{tabular}

PIcb1, phospholipase C, beta 1; Atp1b3, ATPase, Na+/K+ transporting, beta 3 polypeptide; S/c2a4, solute carrier family 2 (facilitated glucose transporter), member 4; Col4a2, collagen, type IV, alpha 2; Cd3d, CD3 antigen, delta polypeptide; I/6st, interleukin 6 signal transducer; Uhrf1, ubiquitin-like, containing PHD and RING finger domains, 1; Tmem109, transmembrane protein 109; Mgp, matrix Gla protein; Npm1, nucleophosmin 1; Synpo2, synaptopodin 2; Nhp2, NHP2 ribonucleoprotein; Tuba1b, tubulin, alpha 1B; Mcm3, minichromosome maintenance deficient 3; Ssrp1, structure specific recognition protein 1; Siva1, SIVA1, apoptosis-inducing factor.

Table 6. Growth parameters in SAMP8 mice

\begin{tabular}{lccc}
\hline & $6 \mathrm{C}$ & $12 \mathrm{~N}$ & $12 \mathrm{~F}$ \\
\hline Body weight (g) & $29.1 \pm 0.86^{\mathrm{a}, \mathrm{b}}$ & $27.6 \pm 0.69^{\mathrm{a}}$ & $31.6 \pm 1.54^{\mathrm{b}}$ \\
Food intake (g/day) & - & $3.42 \pm 0.08$ & $3.82 \pm 0.27$ \\
Caloric intake (kcal/day) & - & $11.8 \pm 0.27$ & $15.9 \pm 1.14^{*}$ \\
Tissue weight (g/100 g body weight) & & & \\
$\quad$ Brain & $1.50 \pm 0.07$ & $1.53 \pm 0.03$ & $1.36 \pm 0.06$ \\
Heart & $0.45 \pm 0.03$ & $0.56 \pm 0.03$ & $0.53 \pm 0.04$ \\
Kidney & $1.68 \pm 0.05$ & $1.81 \pm 0.04$ & $2.02 \pm 0.21$ \\
Lung & $0.87 \pm 0.09^{\mathrm{a}}$ & $1.34 \pm 0.17^{\mathrm{b}}$ & $0.99 \pm 0.13^{\mathrm{a}, \mathrm{b}}$ \\
Liver & $4.28 \pm 0.09^{\mathrm{a}, \mathrm{b}}$ & $4.64 \pm 0.41^{\mathrm{a}}$ & $6.44 \pm 1.07^{\mathrm{b}}$ \\
Pancreas & $1.05 \pm 0.05$ & $0.93 \pm 0.12$ & $0.75 \pm 0.08$ \\
Spleen & $0.33 \pm 0.05$ & $0.72 \pm 0.32$ & $0.43 \pm 0.05$ \\
$\quad$ Thymus & $0.08 \pm 0.02$ & $0.27 \pm 0.17$ & $0.07 \pm 0.01$ \\
White adipose tissue weight & & & \\
$\quad$ Mesenteric & $0.69 \pm 0.10$ & $0.63 \pm 0.16$ & $0.63 \pm 0.20$ \\
Perirenal & $0.65 \pm 0.16$ & $0.44 \pm 0.11$ & $0.66 \pm 0.24$ \\
Epididymal & $1.40 \pm 0.17$ & $1.14 \pm 0.25$ & $1.65 \pm 0.50$ \\
\hline Vally are means & &
\end{tabular}

Values are means $\pm \mathrm{SE}, n=6-9 .{ }^{\mathrm{a}, \mathrm{b}} p<0.05,{ }^{*} p<0.05$ vs $12 \mathrm{~N}$. Food intake and caloric intake are data from 6-month-old.

$\operatorname{diet}(6 \mathrm{C}$ vs $12 \mathrm{~F})$ (Table 5). This suggested that the progression of senescence in the small intestine is delayed by a high-fat diet.

Growth parameters. To examine growth parameters in mice, body weight, food intake and tissue weights were examined (Table 6). There was a significant increase in the body weight in the $12 \mathrm{~F}$ group compared to the $12 \mathrm{~N}$ group. There was no significant difference in the food intake and a significant increase in the caloric intake in the $12 \mathrm{~F}$ group compared to the $12 \mathrm{~N}$ group. There was a significant increase in the lung weight in the $12 \mathrm{~N}$ group compared to the $6 \mathrm{C}$ group. There was a significant increase in the liver weight in the $12 \mathrm{~F}$ group compared to the $12 \mathrm{~N}$ group. There were no significant differences in brain, heart, kidney, pancreas, spleen, thymus, mesenteric adipose tissue, perirenal adipose tissue and epididymal adipose tissue weights. This suggested that body weight reduction with aging is inhibited by a high-fat diet.
Biochemical analyses in plasma and liver. To examine the effect of a high-fat diet on serum and liver in mice, biochemical analyses were performed (Table 7). There was a significant increase in serum TG level in the $12 \mathrm{~F}$ group compared to the $12 \mathrm{~N}$ group. There were significant increases in serum TC and PL levels in the $12 \mathrm{~F}$ group compared to the $6 \mathrm{C}$ and $12 \mathrm{~N}$ groups. There was a significant increase in serum glucose level in the $12 \mathrm{~F}$ group compared to the $6 \mathrm{C}$ and $12 \mathrm{~N}$ groups, but no significant difference in serum insulin level. There was a significant increase in HOMA$\mathrm{IR}$, which is an indicator of insulin resistance, in the $12 \mathrm{~F}$ group compared to the $6 \mathrm{C}$ and $12 \mathrm{~N}$ groups. There were significant increases in liver TG and TC levels in the $12 \mathrm{~F}$ group compared to the $6 \mathrm{C}$ and $12 \mathrm{~N}$ groups, but no significant difference in liver PL level. This suggested that serum and liver lipids are increased and hyperglycemia and fatty liver are induced by a high-fat diet from senescence. 
Table 7. Biochemical parameters in serum and liver

\begin{tabular}{llll}
\hline & $6 \mathrm{C}$ & $12 \mathrm{~N}$ & $12 \mathrm{~F}$ \\
\hline Serum & & & \\
TG (mmol/L) & $1.46 \pm 0.13^{\mathrm{a}} \mathrm{b}$ & $0.96 \pm 0.07^{\mathrm{a}}$ & $3.56 \pm 1.47^{\mathrm{b}}$ \\
TC $(\mathrm{mmol} / \mathrm{L})$ & $2.42 \pm 0.05^{\mathrm{a}}$ & $2.64 \pm 0.12^{\mathrm{a}}$ & $4.76 \pm 0.98^{\mathrm{b}}$ \\
PL (mmol/L) & $2.34 \pm 0.06^{\mathrm{a}}$ & $2.64 \pm 0.12^{\mathrm{a}}$ & $3.60 \pm 0.44^{\mathrm{b}}$ \\
Glucose $(\mathrm{mmol} / \mathrm{L})$ & $10.4 \pm 0.34^{\mathrm{a}}$ & $10.1 \pm 0.91^{\mathrm{a}}$ & $19.4 \pm 3.34^{\mathrm{b}}$ \\
Insulin $(\mathrm{ng} / \mathrm{ml})$ & $1.32 \pm 0.20$ & $1.61 \pm 0.19$ & $2.16 \pm 0.55$ \\
HOMA-IR & $1.00 \pm 0.16^{\mathrm{a}}$ & $1.19 \pm 0.18^{\mathrm{a}}$ & $2.52 \pm 0.53^{\mathrm{b}}$ \\
Liver & & & \\
TG ( $\mu \mathrm{mol} / \mathrm{g}$ tissue) & $13.6 \pm 2.64^{\mathrm{a}}$ & $8.94 \pm 1.83^{\mathrm{a}}$ & $71.3 \pm 14.4^{\mathrm{b}}$ \\
TC $(\mu \mathrm{mol} / \mathrm{g}$ tissue) & $3.42 \pm 0.40^{\mathrm{a}}$ & $5.00 \pm 0.46^{\mathrm{a}}$ & $18.3 \pm 5.11^{\mathrm{b}}$ \\
PL $(\mu \mathrm{mol} / \mathrm{g}$ tissue) & $35.2 \pm 1.93$ & $31.4 \pm 2.37$ & $29.8 \pm 1.83$ \\
\hline
\end{tabular}

Values are means $\pm \mathrm{SE}, n=6-9$. ${ }^{\mathrm{a}, \mathrm{b}} p<0.05$. TG, triacylglycerol; $\mathrm{TC}$, total cholesterol; $\mathrm{PL}$, phospholipid.

\section{Discussion}

In our previous study, we showed the attenuation of lipid absorption ability with aging in mice fed a normal diet. ${ }^{(5)}$ In this study, to establish a way of delaying such attenuation, mice fed a high-fat diet from senescence were used. As a result, it was shown that a high-fat diet inhibits the attenuation of lipid absorption ability with aging by inhibiting the attenuation of cell function and the degeneration of villi in the small intestine with aging.

To examine the alteration of lipid absorption ability with aging and with a high-fat diet, an oral fat tolerance test was performed. TG is absorbed in the small intestine and sent into the blood via lymph. ${ }^{(29,30)}$ In mammals, the serum TG level gradually increases with fat intake and peaks at $3-4 \mathrm{~h}$, and then gradually decreases. ${ }^{(31,32)}$ In this study, the serum TG level was gradually increased by consumption of soybean oil and peaked at 3-4 h, then gradually decreased in all groups (Fig. 1A). AUC for the serum TG level was calculated and there was a significant increase in $\mathrm{AUC}$ in the $12 \mathrm{~F}$ group compared to the $12 \mathrm{~N}$ group (Fig. $2 \mathrm{~B}$ ). AUC is often used as the indicator of the absorption ability of various substances. It is reported that AUC decreases by the attenuation of absorption ability and increases by the enhancement of absorption ability. ${ }^{(33,34)}$ These results suggested that the attenuation of lipid absorption ability with aging is delayed by a high-fat diet.

The effect of progression of senescence caused by aging and a high-fat diet in TG absorption-related tissues (liver, pancreas and small intestine) was examined. Lipid peroxide (TBARS) and p21 mRNA levels were measured to examine the degree of senescence in these tissues. TBARS is an indicator of oxidative stress and increases in aging tissues. ${ }^{(35,36)}$ p21 is a cyclin dependent kinase inhibitor that inhibits cell growth and also increases in aging tissues. ${ }^{(37,38)}$ In this study, there was a significant increase in TBARS level for serum in the $12 \mathrm{~F}$ group compared to the $6 \mathrm{C}$ group and liver in the $12 \mathrm{~F}$ group compared to the $6 \mathrm{C}$ and $12 \mathrm{~N}$ groups. On the other hand, there was a significant increase in p2 1 mRNA level for liver in the $12 \mathrm{~N}$ group compared to the $6 \mathrm{C}$ group (Table 2). These results showed a clear progression of senescence in the liver of 12-month-old SAMP8 mice.

To examine the effect of a high-fat diet on the attenuation of lipid absorption ability with aging, the expression of mRNA for TG absorption-related genes in liver, pancreas and small intestine was measured. In the process of lipid absorption, first, TG is emulsified by bile acid, then hydrolyzed by pancreatic lipase. Lipid is then absorbed in the small intestine and is resynthesized into TG. Finally, TG is imported into the chylomicron and is sent into the blood via the lymph. ${ }^{(29)}$ In this study, the following six genes mainly involved in this pathway were measured: Cyp7a1, which is crucial for bile acid synthesis in the liver; Clps, Plrp2 and Ptl, which are required for efficient TG hydrolysis in the pancreas;
Fabp2, which transports free fatty acid; and Mttp, which brings TG into chylomicrons in the small intestine. ${ }^{(39-42)}$ There were no significant differences in mRNA levels of all genes (Table 3 ). This suggested that there was no change in mRNA levels for TG absorption-related genes in relation to the delay of attenuation of lipid absorption ability by a high-fat diet.

We examined the morphology of lipid absorption-related tissues because lipid absorption-related genes did not change by a high-fat diet in relation to the delay of attenuation of lipid absorption ability with aging. Various tissues play a role in lipid absorption. The small intestine is the most important tissue for every nutrient including lipid. ${ }^{(43,44)}$ Therefore, in this study, small intestine morphology was examined by histological analysis. As a result, there was a significant decrease in length of villus in the small intestine in the $12 \mathrm{~N}$ group and a significant increase in the $12 \mathrm{~F}$ group compared to the 6C group (Fig. 2). In the small intestine, the surface area decreases due to degeneration of villi with aging and this plays a role in the attenuation of nutrient absorption ability with aging. ${ }^{(45)}$ Therefore, these results showed that the delay of degeneration of villi in the small intestine with aging was inhibited by a high-fat diet from senescence.

To examine cell functions in the small intestine more closely, DNA microarray analysis was performed (Table 4 and 5). As a result, mRNA levels of 16 genes increased in the $12 \mathrm{~N}$ group compared to the $6 \mathrm{C}$ group and the expression of these genes was diminished in the $12 \mathrm{~F}$ group. It is known that many of the genes we found show high expression or overexpression in inflammation and stress which are related to the attenuation of cell functions. Especially, interleukin 6 signal transducer (Il6st) and ubiquitinlike, containing PHD and RING finger domains, 1 (Uhrf1) show high expression in inflammation and aging which induce the attenuation of cell functions. ${ }^{(46,47)}$ Nucleophosmin 1 (Npm1) also shows high expression in stress and aging. ${ }^{(48)}$ Inflammation and stress in the small intestine induce the degeneration of villi, the attenuation of nutrient absorption ability, and malnutrition. ${ }^{(49-51)}$ These results showed that the attenuation of cell functions in the small intestine with aging was inhibited by a high-fat diet and induced the delay of attenuation of lipid absorption ability.

To examine the effect of a high-fat diet from senescence on body composition, body weight and tissue weights were measured. As a result, there was a significant increase in the body weight in the $12 \mathrm{~F}$ group compared to the $12 \mathrm{~N}$ group. However, there was no significant difference in the weight of visceral fat (Table 6). Body weight and weight of visceral fat increase with a high-fat diet. ${ }^{(3,52)}$ However, in this study, only body weight increased. We observed that visceral fat gradually decreased in mice which showed progression of senescence and then approached death. ${ }^{(2)}$ Therefore, a high-fat diet may be able to inhibit this phenomenon. However, in this study, there was no significant difference in weight of visceral fat, which is thought to be mainly 
due to the difference in the mice strain. Aged mice often show various phenomena in their bodies due to differences in the mice strain. For example, in our previous study, we showed the attenuation of lipid absorption ability with aging in ICR mice; the mechanism was that the expression of pancreatic lipase decreased with the progression of senescence in the pancreas. ${ }^{(5)}$ However, in this study, we showed the attenuation of lipid absorption ability, whereas we did not show the progression of senescence and the alteration of expression of pancreatic lipase in the pancreas. The different mechanism emerged due to the difference in mice strain. The lifespan of ICR mice is about two years and senescence progresses slowly in contrast to SAMP8 mice. ${ }^{(53)}$ Moreover, in ICR mice, a high-fat diet easily affects adipose tissues and so the mice are used in various studies related to a high-fat diet and adipose tissues. ${ }^{(54,55)}$ Therefore, it is thought that a high-fat diet can easily affect adipose tissues even if senescence progresses. On the other hand, the lifespan of SAMP8 mice is about a year and senescence progresses quickly, ${ }^{(16,17)}$ reaching significant senescence at 12 months old. It was reported that a high-fat diet had little effect on adipose tissues in senescence-accelerated mice such as SAMP8 mice when senescence progressed sufficiently. ${ }^{(3)}$ Therefore, it was thought that a high-fat diet had little effect on adipose tissues in SAMP8 mice in contrast to ICR mice as senescence progresses.

To examine the effect of a high-fat diet from senescence on serum and liver parameters, serum and liver biochemical analyses were performed. As a result, there were significant increases in serum TG level, TC level, PL level, glucose level and HOMA-IR in the $12 \mathrm{~F}$ group and there were also significant increases in liver TG level and TC level in the 12F group (Table 7). The high-fat diet from senescence induced hyperglycemia and lipid accumulation in the liver, which induce aging-related diseases such as diabetes and fatty liver. ${ }^{(3,56)}$ Therefore, it was shown that a high-fat diet from senescence not only had the positive effect of delaying the attenuation of lipid absorption ability with aging, but also had the negative effects of diabetes and fatty liver.

It is also known that high-fat diet negatively affects circulatory system in common with inducing fatty liver and diabetes. ${ }^{(57)}$ So, it is interesting that high-fat diet intake from senescence has influence on cardiovascular parameter. However, in this study, we did not examine cardiovascular parameters because the ability of gastrointestinal tract to lipid was the most important element. In this study, we measured serum total cholesterol which is one of the cardiovascular parameter. As a result, there was a significant increase in serum total cholesterol in the $12 \mathrm{~F}$ group compared to the $6 \mathrm{C}$ and $12 \mathrm{~N}$ groups. High-fat diet intake from senescence negatively affects circulatory system because high level of serum total cholesterol induces coronary heart disease. ${ }^{(58)}$ In the future, we will examine the effect of cardiovascular parameters such as blood pressure on malnutrition with aging and improvement of this malnutrition.

The elderly who is not malnutrition has a long life-span because elderly mortality rate of malnutrition is high. ${ }^{(59)}$ However, in this study, high-fat diet intake from senescence induced simultaneously the improvement of decreased ability of the gastrointestinal tract with aging which can resolve malnutrition and fatty liver and diabetes which induce life shortening. It is interesting that high-fat diet intake from senescence has influence on life-span. We made survival curves in the feeding period of this study. As a result, there was no significant difference in the life-span. $(12 \mathrm{~N}$ vs $12 \mathrm{~F}, p=0.397$ ) (Supplemental Fig. $1 *$ ). However, mice which consumed high-fat diet showed increased mortality. This suggested that fatty liver and diabetes by high-fat diet intake from senescence are a strong influence on the life-span than the improvement of malnutrition by high-fat diet intake from senescence. So, in the future, we will explore the diet and functional components which can improve malnutrition with aging and inhibit fatty liver and diabetes.

In conclusion, in our previous study, we showed the attenuation of lipid absorption ability with aging, ${ }^{(5)}$ and in this study, we noted a high-fat diet from senescence as a way to resolve this problem and showed that the attenuation of lipid absorption ability was delayed by the inhibition of attenuation of cell functions and degeneration of villi in the small intestine. However, it was also shown that consuming a high-fat diet from senescence induced diabetes and fatty liver as with a high-fat diet from a younger age. In the future, we will study ways to delay simultaneously the attenuation of lipid absorption ability with aging and inhibit aging-related diseases.

\section{Acknowledgments}

This study was supported by Integration research for agriculture and interdisciplinary fields for Bio-oriented Technology Research Advancement Institution (BRAIN), Japan.

\section{Conflict of Interest}

No potential conflicts of interest were disclosed.

\section{References}

1 Zhou Y, Dong Y, Xu QG, et al. Mussel oligopeptides protect human fibroblasts from hydrogen peroxide $\left(\mathrm{H}_{2} \mathrm{O}_{2}\right)$-induced premature senescence. Arch Gerontol Geriatr 2014; 58: 293-299.

2 Honma T, Yanaka M, Tsuduki T, Ikeda I. Increased lipid accumulation in liver and white adipose tissue in aging in the SAMP10 mouse. J Nutr Sci Vitaminol (Tokyo) 2011; 57: 123-129.

3 Honma T, Shinohara N, Ito J, et al. High-fat diet intake accelerates aging, increases expression of Hsd11b1, and promotes lipid accumulation in liver of SAMP10 mouse. Biogerontology 2012; 13: 93-103.

4 Cuesta S, Kireev R, García C, Rancan L, Vara E, Tresguerres JA. Melatonin can improve insulin resistance and aging-induced pancreas alterations in senescence-accelerated prone male mice (SAMP8). Age (Dordr) 2013; 35: 659-671.

5 Yamamoto K, Kitano Y, Shuang E, et al. Decreased lipid absorption due to reduced pancreatic lipase activity in aging male mice. Biogerontology 2014; 15: 463-473.

6 Wijnhoven HA, Schilp J, van Bokhorst-de van der Schueren MA, et al. Development and validation of criteria for determining undernutrition in community-dwelling older men and women: The Short Nutritional Assessment Questionnaire 65+. Clin Nutr 2012; 31: 351-358.

7 Benković V, Kolčić I, Ivičević Uhernik. The economic burden of diseaserelated undernutrition in selected chronic diseases. Clin Nutr 2014; 4: 689693

8 Winter TA, O'Keefe SJ, Callanan M, Marks T. Effect of severe undernutrition and subsequent refeeding on gut mucosal protein fractional synthesis in human subjects. Nutrition 2007; 23: 29-35.

9 Zhang Y, Fischer KE, Soto V, et al. Obesity-induced oxidative stress, accelerated functional decline with age and increased mortality in mice. Arch Biochem Biophys 2015; 576: 39-48.

10 Shibata $\mathrm{H}$. The relationship of fat intakes to health in the elderly. Oleoscience 2013; 13: 17-23 (in Japanese).

11 Petit V, Arnould L, Martin P, et al. Chronic high-fat diet affects intestinal fat absorption and postprandial triglyceride levels in the mouse. J Lipid Res 2007; 48: 278-287.

12 Takeda T, Hosokawa M, Takeshita S, et al. A new murine model of accelerated senescence. Mech Ageing Dev 1981; 17: 183-194.

13 Takeda T, Hosokawa M, Higuchi K. Senescence-accelerated mouse (SAM): a novel murine model of accelerated senescence. J Am Geriatr Soc 1991; 39: 911-919.

14 Takeda T, Matsushita T, Kurozumi M, Takemura K, Higuchi K, Hosokawa 
M. Pathobiology of the senescence-accelerated mouse (SAM). Exp Gerontol 1997; 32: 117-127.

15 Butterfield DA, Poon HF. The senescence-accelerated prone mouse (SAMP8): a model of age-related cognitive decline with relevance to alterations of the gene expression and protein abnormalities in Alzheimer's disease. Exp Gerontol 2005; 40: 774-783.

16 Tsuduki T, Honma T, Nakagawa K, Ikeda I, Miyazawa T. Long-term intake of fish oil increases oxidative stress and decreases lifespan in senescenceaccelerated mice. Nutrition 2011; 27: 334-337.

17 Honma T, Kitano Y, Kijima R, et al. Comparison of the health benefits of different eras of Japanese foods: lipid and carbohydrate metabolism focused research. Nippon Shokuhin Kagaku Kogaku Kaishi 2013; 60: 541-553 (in Japanese).

18 Tsuduki T, Tokuyama Y, Igarashi M, Miyazawa T. Tumor growth suppression by alpha-eleostearic acid, a linolenic acid isomer with a conjugated triene system, via lipid peroxidation. Carcinogenesis 2004; 25: 1417-1425.

19 Tsuduki T, Kuriyama K, Nakagawa K, Miyazawa T. Tocotrienol (unsaturated vitamin E) suppresses degranulation of mast cells and reduces allergic dermatitis in mice. J Oleo Sci 2013; 62: 825-834.

20 Ohkawa H, Ohishi N, Yagi K. Assay for lipid peroxides in animal tissues by thiobarbituric acid reaction. Anal Biochem 1979; 95: 351-358.

21 Shinohara N, Tsuduki T, Ito J, et al. Jacaric acid, a linolenic acid isomer with a conjugated triene system, has a strong antitumor effect in vitro and in vivo. Biochim Biophys Acta 2012; 1821: 980-988.

22 Tsuduki T, Kambe T, Shibata A, Kawakami Y, Nakagawa K, Miyazawa T. Conjugated EPA activates mutant p53 via lipid peroxidation and induces p53-dependent apoptosis in DLD-1 colorectal adenocarcinoma human cells. Biochim Biophys Acta 2007; 1771: 20-30.

23 Tsuduki T, Kawakami Y. Tumor angiogenesis suppression by alphaeleostearic acid, a linolenic acid isomer with a conjugated triene system, via peroxisome proliferator-activated receptor gamma. Carcinogenesis 2008; 29: 797-806.

24 Honma T, Tsuduki T, Sugawara S, et al. Aging decreases antioxidant effects and increases lipid peroxidation in the Apolipoprotein E deficient mouse. $J$ Clin Biochem Nutr 2013; 52: 234-240.

25 Shibata A, Nakagawa K, Sookwong P, Tsuzuki T, Oikawa S, Miyazawa T. Tumor anti-angiogenic effect and mechanism of action of delta-tocotrienol. Biochem Pharmacol 2008; 76: 330-339.

26 Tsuzuki T, Kawakami Y, Suzuki Y, Abe R, Nakagawa K, Miyazawa T. Intake of conjugated eicosapentaenoic acid suppresses lipid accumulation in liver and epididymal adipose tissue in rats. Lipids 2005; 40: 1117-1123.

27 Tsuzuki T, Kawakami Y, Nakagawa K, Miyazawa T. Conjugated docosahexaenoic acid inhibits lipid accumulation in rats. $J$ Nutr Biochem 2006; 17: $518-524$.

28 Rouser G, Fkeischer S, Yamamoto A. Two dimensional then layer chromatographic separation of polar lipids and determination of phospholipids by phosphorus analysis of spots. Lipids 1970; 5: 494-496.

29 Clement G. The digestion and absorption of fats. J Physiol (Paris) 1964; 56: 111-192.

30 Uchida A, Lee HJ, Cheng JX, Buhman KK. Imaging cytoplasmic lipid droplets in enterocytes and assessing dietary fat absorption. Methods Cell Biol 2013; 116: 151-166.

31 Watson TD, Mackenzie JA, Stewart JP, Barrie J. Use of oral and intravenous fat tolerance tests to assess plasma chylomicron clearance in dogs. Res Vet Sci 1995; 58: 256-262.

32 Wu D, Liu Q, Wei S, Zhang YA, Yue F. A preliminary report on oral fat tolerance test in rhesus monkeys. Lipids Health Dis 2014; 13: 11.

33 Schramm DD, Karim M, Schrader HR, et al. Food effects on the absorption and pharmacokinetics of cocoa flavanols. Life Sci 2003; 73: 857-869.

34 Powell DR, Smith M, Greer J, et al. LX4211 increases serum glucagon-like peptide 1 and peptide YY levels by reducing sodium/glucose cotransporter 1 (SGLT1)-mediated absorption of intestinal glucose. J Pharmacol Exp Ther 2013; 345: 250-259.

35 Sugawara S, Honma T, Ito J, Kijima R, Tsuduki T. Fish oil changes the lifespan of Caenorhabditis elegans via lipid peroxidation. J Clin Biochem Nutr 2013; 52: 139-145.

36 Schoffen JP, Santi Rampazzo AP, Cirilo CP, et al. Food restriction enhances oxidative status in aging rats with neuroprotective effects on myenteric neuron populations in the proximal colon. Exp Gerontol 2014; 51: 54-64.

37 Villeneuve NF, Sun Z, Chen W, Zhang DD. Nrf2 and p21 regulate the fine balance between life and death by controlling ROS levels. Cell Cycle 2009; 8:
3255-3256.

38 Choudhery MS, Khan M, Mahmood R, Mehmood A, Khan SN, Riazuddin $\mathrm{S}$. Bone marrow derived mesenchymal stem cells from aged mice have reduced wound healing, angiogenesis, proliferation and anti-apoptosis capabilities. Cell Biol Int 2012; 36: 747-753.

39 Murashita K, Yoshiura Y, Chisada S, et al. Postprandial response and tissue distribution of the bile acid synthesis-related genes, cyp7a1, cyp8b1 and shp, in rainbow trout Oncorhynchus mykiss. Comp Biochem Physiol A Mol Integr Physiol 2013; 166: 361-369.

40 Ren J, Chen Z, Zhang W, et al. Increased fat mass and insulin resistance in mice lacking pancreatic lipase-related protein 1. J Nutr Biochem 2011; 22: 691-698.

41 Venold FF, Penn MH, Thorsen J, et al. Intestinal fatty acid binding protein (fabp2) in Atlantic salmon (Salmo salar): Localization and alteration of expression during development of diet induced enteritis. Comp Biochem Physiol A Mol Integr Physiol 2013; 164: 229-240.

42 Wetterau JR, Lin MC, Jamil H. Microsomal triglyceride transfer protein. Biochim Biophys Acta 1997; 1345: 136-150.

43 Breen DM, Rasmussen BA, Côté CD, Jackson VM, Lam TK. Nutrientsensing mechanisms in the gut as therapeutic targets for diabetes. Diabetes 2013; 62: 3005-3013.

44 Zhang LS, Xu M, Yang Q, Lou D, Howles PN, Tso P. ABCG5/G8 deficiency in mice reduces dietary triacylglycerol and cholesterol transport into the lymph. Lipids 2015; 50: 371-379.

45 Drozdowski L, Thomson AB. Aging and the intestine. World J Gastroenterol 2006; 12: 7578-7584.

46 Gottardo L, De Cosmo S, Zhang YY, et al. A polymorphism at the IL6ST (gp130) locus is associated with traits of the metabolic syndrome. Obesity (Silver Spring) 2008; 16: 205-210.

47 Mudbhary R, Hoshida Y, Chernyavskaya Y, et al. UHRF1 overexpression drives DNA hypomethylation and hepatocellular carcinoma. Cancer Cell 2014; 25: 196-209.

48 Lee N, Kim DK, Kim ES, et al. Comparative interactomes of SIRT6 and SIRT7: implication of functional links to aging. Proteomics 2014; 14: 1610 1622.

49 Darmon N, Pélissier MA, Heyman M, Albrecht R, Desjeux JF. Oxidative stress may contribute to the intestinal dysfunction of weanling rats fed a low protein diet. J Nutr 1993; 123: 1068-1075.

50 Kaynar L, Cetin A, Hacioglu SK, et al. Efficacy of royal jelly on methotrexateinduced systemic oxidative stress and damage to small intestine in rats. Afr $J$ Tradit Complement Altern Med 2012; 9: 412-417.

51 Saha P, Manoharan P, Arthur S, Sundaram S, Kekuda R, Sundaram U. Molecular mechanism of regulation of villus cell Na-K-ATPase in the chronically inflamed mammalian small intestine. Biochim Biophys Acta 2015; 1848: $702-711$.

52 Tsuduki T, Kikuchi I, Kimura T, Nakagawa K, Miyazawa T. Intake of mulberry 1-deoxynojirimycin prevents diet-induced obesity through increases in adiponectin in mice. Food Chem 2013; 139: 16-23.

53 Ray MA, Johnston NA, Verhulst S, Trammell RA, Toth LA. Identification of markers for imminent death in mice used in longevity and aging research. $J$ Am Assoc Lab Anim Sci 2010; 49: 282-288.

54 Cho AS, Jeon SM, Kim MJ, et al. Chlorogenic acid exhibits anti-obesity property and improves lipid metabolism in high-fat diet-induced-obese mice. Food Chem Toxicol 2010; 48: 937-943.

55 Okamoto M, Irii H, Tahara Y, et al. Synthesis of a new [6]-gingerol analogue and its protective effect with respect to the development of metabolic syndrome in mice fed a high-fat diet. J Med Chem 2011; 54: 6295-6304.

56 E S, Kijima R, Honma T, et al. 1-Deoxynojirimycin attenuates high glucoseaccelerated senescence in human umbilical vein endothelial cells. Exp Gerontol 2014; 55: 63-69.

57 Vargas-Robles H, Rios A, Arellano-Mendoza M, Escalante BA, Schnoor M. Antioxidative diet supplementation reverses high-fat diet-induced increases of cardiovascular risk factors in mice. Oxid Med Cell Longev 2015; 2015: 467471.

58 Tanabe N, Iso H, Okada K, et al. Serum total and non-high-density lipoprotein cholesterol and the risk prediction of cardiovascular events- the JALS-ECC-. Circ J 2010; 74: 1346-1356.

59 Lim SL, Ong KC, Chan YH, Loke WC, Ferguson M, Daniels L. Malnutrition and its impact on cost of hospitalization, length of stay, readmission and 3year mortality. Clin Nutr 2012; 31: 345-350. 